\title{
Universiteit
}

Leiden

The Netherlands

\section{Communal Violence and Child Psychosocial Well- being: Qualitative Findings from Poso, Indonesia}

Tol, W.A.; Reis, R.; Susanty, D.; Jong, J.T.V.M. de

\section{Citation}

Tol, W. A., Reis, R., Susanty, D., \& Jong, J. T. V. M. de. (2010).

Communal Violence and Child Psychosocial Well-being: Qualitative Findings from Poso, Indonesia. Transcultural Psychiatry, 47(1), 112-135. doi:10.1177/1363461510364573

Version: $\quad$ Not Applicable (or Unknown)

License: $\quad$ Leiden University Non-exclusive license

Downloaded from: $\quad$ https://hdl.handle.net/1887/117190

Note: To cite this publication please use the final published version (if applicable). 


\section{Transcultural Psychiatry \\ http://tps.sagepub.com/}

Communal Violence and Child Psychosocial Well-being: Qualitative Findings from Poso, Indonesia

Wietse A. Tol, Ria Reis, Dessy Susanty and Joop T.V.M. de Jong

Transcultural Psychiatry 2010 47: 112

DOI: $10.1177 / 1363461510364573$

The online version of this article can be found at:

http://tps.sagepub.com/content/47/1/112

Published by:

@SAGE

http://www.sagepublications.com

On behalf of:

Division of Social \& Transcultural Psychiatry, Department of Psychiatry, McGill University

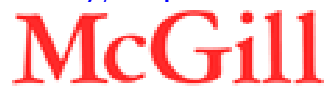

World Psychiatric Association

Additional services and information for Transcultural Psychiatry can be found at:

Email Alerts: http://tps.sagepub.com/cgi/alerts

Subscriptions: http://tps.sagepub.com/subscriptions

Reprints: http://www.sagepub.com/journalsReprints.nav

Permissions: http://www.sagepub.com/journalsPermissions.nav

Citations: http://tps.sagepub.com/content/47/1/112.refs.html

>> Version of Record - May 28, 2010

What is This? 


\title{
transcultural psychiatry
}

February

2010

ARTICLE

\section{Communal Violence and Child Psychosocial Well-being: Qualitative Findings from Poso, Indonesia}

\author{
WIETSE A. ToL \\ HealthNet TPO
}

\author{
RIA REIS \\ University of Amsterdam
}

DESSY SUSANTY

Church World Service - Indonesia

JoOP T.V.M. DE JONG

VU University Medical Center Amsterdam

\begin{abstract}
This exploratory study examined the health care system in relation to communal violence-related psychosocial wellbeing in Poso, Indonesia, as preparation for conducting a cluster randomized trial of a psychosocial intervention. We employed focus groups with children $(N=9)$, parents $(N=11)$, and teachers $(N=8)$, as well as semi-structured interviews with families affected by communal violence $(N=42)$, and key informants $(N=33)$. An interrelated set of problems was found that included poverty, an indigenized trauma construct, morally inappropriate behavior, interreligious tensions, and somatic problems. Participants emphasized socialecological interactions between concerns at different systemic levels,
\end{abstract}


although problems were mainly addressed through informal care by families. The programmatic and research implications of these findings are discussed.

Key words children $\cdot$ Indonesia $\cdot$ political violence $\bullet$ psychosocial $\bullet$ war

\section{INTRODUCTION}

Since World War II, a body of scientific literature has developed that documents the impact of armed conflict on the psychosocial and mental wellbeing of children and adolescents. ${ }^{1}$ With the changing nature of armed conflicts after the Cold War, from inter-state into intra-state conflicts in populated areas, it has been increasingly recognized that children are vulnerable to the negative effects of armed conflicts (Pedersen, 2002; Wexler, Branski, \& Kerem, 2006). Most of the research on the impact of armed conflict on psychosocial and mental wellbeing of children has been quantitative, informed by a biomedical perspective, focusing on psychiatric disorders as described in classification systems developed in highincome settings (Betancourt \& Williams, 2008).

Current literature shows a shift of focus from an emphasis on Posttraumatic Stress Disorder (PTSD) to more general mental health and psychosocial problems that can emerge at different stages of child development. In addition, there has been increased attention to factors that influence mental health outcomes, such as cultural context, family variables and gender. Often mentioned disorders, besides PTSD, are major depression, anxiety disorders, dissociative disorders, aggression, somatic symptoms, substance abuse (with adolescents), disturbed academic functioning, and interference in developmental tasks, e.g., through loss of previously acquired bowel control (Barenbaum, Ruchkin, \& SchwabStone, 2004; Berman, 2001; Joshi \& O’Donnell, 2003; Shaw, 2003). In 2001, Stichick proposed a paradigm shift from a single focus on traumatic stress to an examination of the multilevel and multimodal effects of chronic stress situations, protective and mediating factors, and the role of cultural context, gender, and the type of conflict situation (Stichick, 2001). Concurrently, in the last decade there seems to have been increasing attention paid to the ways that contextual variables shape the relations between war and psychosocial well-being (Boothby, Strang, \& Wessels, 2006; De Jong, 2002; Miller \& Rasco, 2004).

In addition to this quantitative research, a smaller sociological and anthropological body of research has enquired into the consequences of armed conflicts and violence on children and adolescents, using mainly qualitative (ethnographic, narrative) methodologies (Miller, Kulkarni, \& Kushner, 2006). This literature has often been critical of assumptions inherent in the biomedical approach, including its lack of attention to 
sociocultural and historical context; child agency; children's perspectives and engagements with this context; the diversity in notions of childhood and transitions to adulthood in different cultural contexts; the construction of the social category of childhood in contexts of violence; and, the resources available in communities to deal with adversity (e.g., Boyden, 2000; Boyden \& de Berry, 2006; Das \& Reynolds, 2003; Hart \& Tyrer, 2006). For example, Korbin (2003) notes that the development of the anthropological literature on children and violence has been constrained by the struggle with the concept of the child as both victim and aggressor. Little cross-referencing takes place between the quantitative and qualitative paradigms (De Jong \& Van Ommeren, 2002; Summerfield, 2000).

This study used a qualitative approach to examine the ways in which an existing health care system deals with violence-affected children as part of a public mental health program that aims to provide services to political violence-affected communities. It tried to do so in a relatively short time, by using available research resources and methods in existing humanitarian organizations trained in rural appraisal techniques (see e.g., Arafat \& Boothby, 2003; World Health Organization, 2001). The exploratory study functioned as a pre-study to a cluster randomized trial aimed at evaluating outcomes of a school-based psychosocial intervention (Tol et al., 2008). Though randomized controlled trials are the gold standard in evaluation of health interventions, they generally do not provide answers to other questions important to public health, such as how distress is experienced, what other help-seeking strategies are common and what services are available (Hohmann \& Shear, 2002). Our main research questions were therefore (1) "How do people in violence-affected communities describe the psychosocial impact of armed conflict on children?" and (2) "What is being done in violence-affected communities to address this impact?" The results of the study were expected to provide input to the design and evaluation of the public mental health program (cf., De Jong \& Van Ommeren, 2002).

\section{Methodology}

\section{Setting and Communal Violence Background}

Data were collected in the Poso district of the province of Central Sulawesi in Indonesia. Central Sulawesi is one of the five provinces of Sulawesi, the fourth largest island in the archipelago of Indonesia. It is one of the poorer provinces of Indonesia with $24.9 \%$ of the population living below the poverty line, with agriculture (coconut, cloves, cocoa) as the largest source of income. Central Sulawesi is home to a number of ethnic groups, 
including the Pamona, Bugis, Makassarese, Togian, Balinese, Javanese, and Chinese (Brown, Tajima, \& Hadi, 2005). Protestant groups have traditionally inhabited the highlands in the interior of the province (indigenous groups converted by Dutch colonizers), whereas Muslim groups (influenced through Muslim traders prior to Dutch domination) inhabited coastal areas. These groups generally lived in peaceful coexistence and were allied through exchange of commodities, military support, and elite marriages. These alliances were damaged by Dutch colonizers, who wanted to build a Protestant buffer against perceived Islamic threats (Aragon, 2001).

The causes of large-scale communal violence between Protestant and Muslim groups include (1) changes in economic relations between ethnic/religious groups, brought about by a loss of the colonially-inherited Protestant domination of governmental positions and educational advantage and a comparatively limited profit for Protestants from the new timber industry and cash crop farming, (2) migration and related demographic changes brought about by state transmigration policies introducing Javanese and Balinese to the region and spontaneous migration by Bugis from the southern part of the island, (3) indigenous groups' decreased access to ancestral land, (4) an increased competition for resources caused by the Asian economic crisis, (5) government decentralization at the national level, raising the stakes for local government control with its concomitant profits, and (6) a weak legal/state structure and inadequate state response to eruptions of violence, causing rival groups to resort to vigilantism for retribution and self-protection (Aragon, 2001; Brown et al., 2005).

Communal violence started in 1998 and has generally been divided into several phases. The first two phases (December 1998 to April 2000 and April to May 2000) started with drunken fights between youths during local government elections, which led to large-scale rioting. This included the burning of houses, businesses and churches. The third phase (May to July 2000) can be seen as a retaliation by Protestant groups to the unchecked, predominantly Muslim violence during the first two phases, and resulted in large-scale killing and the burning of houses of Muslims (Aragon, 2001). This phase was followed by an intensification through more organized violence (phase four; July 2001 to December 2001) and the arrival of radical Muslim militant groups. After phase four an attempt at reconciliation was made. The resultant Malino Accords of December 2001 were able to halt large-scale community rioting and reduced the level of violence. Since then violence has been less overt with the adoption of terror tactics. This has involved mysterious shootings, rumors and occasional bombings resulting in mainly non-Muslim deaths. Conservative estimates put the number of deaths up to 2003 at around 700 
and the number of people displaced at 110,000 (Brown et al., 2005; Human Rights Watch, 2002; International Crisis Group, 2004).

Our study participants reported experiencing forced displacement during the phases of violence, mostly to areas in which their own religion predominated. Their experiences ranged from traveling by car to urban areas to hazardous walks of several days while exposed to harsh weather. Some reported experiencing a lack of nutrition, illness, and strong negative emotions about the destruction of one's property or village. In addition, participants reported hearing of violent acts (e.g., attacks on family members, killings, and bomb explosions), directly witnessing violent events (church shootings, bombings, killings) and experiencing attacks on themselves and their villages.

\section{Participants and Site Selection}

We selected communities that were similar to those in areas where program implementation was planned in terms of (1) livelihood (i.e., mainly farming communities), (2) religious/ethnic division (i.e., mixed religious areas), and (3) experience of conflict-related events. We focused on school-aged children (6-12-year olds) and we selected children aged around 12 years for the focus groups. First, data collection started with community meetings. Village leaders and religious leaders were asked to organize a meeting with people from the village in a central community space. In these meetings, research objectives were presented and permission was sought. Subsequently, people present drew up lists of key informants and schools. A broad category of people identified as community experts on children's problems were approached for semistructured interviews. Moreover, principals of schools and village heads were approached during or after these community meetings to ask if children, parents, and teachers would be interested in joining focus group discussions. Second, through snowball sampling, key informants who had been approached for interviews were asked to identify other participants available in their communities. Third, key informants were asked if they were willing to facilitate contact with the research team for semistructured interviews with villagers they knew who were experiencing difficulties of the sort discussed.

\section{IntervieWs AND PROCEDURES}

We carried out 28 focus groups with a total of 265 participants; 9 were carried out with children (80 participants altogether), 11 with parents (128 participants), and 8 with teachers (57 participants). Over half (56.2\%) of the participants in the focus groups were female. Forty-three percent 
( $n=114)$ identified as Christian, $42.6 \%(n=113)$ as Muslim, and $10.6 \%$ $(n=28)$ as Hindu; data on religion were missing for the remaining $3.8 \%$ $(n=10)$. Themes covered in focus group discussions included the perceived impact of armed conflict, the perceived relevance of psychosocial problems, and methods used to cope with the impact of conflict. Forty-two people were interviewed as part of semi-structured interviews held with families affected by the conflict. More than half of these participants were mothers $(n=22)$, followed in frequency by fathers $(n=8)$, children $(n=5)$, extended family members $(n=5)$, and a foster mother $(n=1)$. An equal number of participants in semi-structured interviews were male and female; the majority identified as Christian $(78.6 \%, n=33)$, $16.7 \%(n=7)$ as Muslim, and $4.8 \%(n=2)$ as Hindu. The themes discussed in these interviews included the cause of the problems experienced by the families, the modes of help-seeking they have employed, the role of different stakeholders involved in the help-seeking process, and the current state of problems. Finally, an additional 33 semi-structured interviews were held with key informants, including school personnel $(n=10)$, massage healers $(n=8)$, medical personnel $(n=5)$, and religious leaders and educators from the Christian $(n=6)$, Muslim $(n=3)$ and Hindu $(n=1)$ communities. Most of the key informants were female $(67 \%$, $n=22)$ and Christian $(72.7 \%, n=24) ; 24.2 \%(n=8)$ were Muslim and $3 \%(n=1)$ Hindu. The themes covered in these interviews included informants' views on the current problems and the impact of the conflict, as well as the healing methods they have employed.

All interviews were pre-formatted and were of a semi-structured nature. Informed consent was obtained from all participants (in the case of children, also from parents). Data were collected by a team of four local interviewers who had at least a Bachelors degree in a social science, guided by a Muslim research coordinator from Java (DS). They were trained for four weeks in interviewing skills, the use of the semi-structured questionnaires, field practice, data reporting and basic data analysis (WT). Interviews were mainly conducted in Bahasa Indonesia, and sometimes Posonese, and records were made in Bahasa Indonesia. Ethical approval for the study was granted by the VU University Amsterdam. Data collection took place between August and November 2005.

\section{ANALYSIS}

Data analysis was carried out on translated, transcribed interviews that had been tape-recorded. Data analysis followed grounded theory procedures as outlined by Strauss and Corbin, with the use of ATLAS.ti 5 for Windows. In a first step open and axial coding was done to draft a codefilter using a selection of interviews until data saturation took place. 
It became apparent during this first step that concepts and dimensions emerging from the data could best be organized into an analytical framework on the lines of an ecological approach, i.e., coding for child-, family-, peer-, school-, and community-level impacts and resources. This framework served as a data-grounded heuristic tool to highlight the importance of differential impacts at different social ecological levels, as well as interaction between levels. In a second step, this codefilter was tested with a next selection of interviews, to look at categories formed and their properties and dimensions (selective coding). In a third step, all data was coded with the refined codefilters and more selective coding took place. Finally, further axial and selective coding was done to explore relationships within data sets between and within categories.

Findings are presented below with the help of Kleinman's (1980) description of the health care system; (1) the popular sector ("the lay, nonprofessional, non-specialist, popular culture arena in which illness is first defined and health care activities are initiated" (Kleinman, 1980, p. 50), (2) the folk sector (a sector that overlaps with both the popular and professional sectors, described by Kleinman as non-professional, nonbureaucratic, but specialized, consisting of both sacred and secular parts), and (3) the professional sector (consisting of the organized healing professions, e.g., Ayurvedic or allopathic care). We chose to present data in these sectors, rather than a somewhat straightforward presentation of problems and resources per social-ecological domains. This was done to emphasize the relatedness of problems presented within sectors, while at the same time showing some of the concerns shared by health care system actors. Below we describe for each sector the problems that participants prioritized, along with common responses to these problems. Further categorization of problem descriptions within sectors reflects emic categories. All quotes and words translated from Bahasa Indonesia in the sections below are italicized.

\section{Results}

\section{Popular Sector: The Family}

Most important psychosocial problems are managed first and foremost in the family. From semi-structured interviews with affected families, including children themselves, four main (interrelated) problems emerged: (1) problems related to lack of income, (2) trauma and fears, (3) somatic problems, and (4) "morally inappropriate behavior." These problems and treatment approaches are described below with case illustrations. (Names and details have been changed to maintain confidentiality.) 


\section{Loss of Income and its Consequences}

Throughout all interviews, participants most strongly emphasized and prioritized a group of problems related to a lack of income. Poverty was reported as a problem by many families, due to the destruction of houses, belongings, and a lost opportunity for income generation when plantation gardens were destroyed, sold, or neglected during displacement ("Plantation gardens were left during the conflict. When we came back to the village, we had to start again from zero").

In this respect, child and adult participants stressed how social events in their communities, schools, families were linked to themselves. The loss of productive plantation gardens makes it difficult for parents to pay for school fees, healthcare costs, children's clothing and other expenses. People who completely lost land are now working for others who still own plantation gardens ("Becoming a farm worker is like being a chicken; it scratches in the morning for lunch, it scratches in the evening for dinner"). Children feel that there is increased inequality in communities, with some families experiencing more economic problems than others, and feel sorry for their friends who cannot go to school. Children of families that cannot pay the school fees often drop out rather than experience the shame of being reprimanded by teachers and teased, and of not having the appropriate clothes, or school materials. This problem is compounded by children having missed classes due to displacement, the previous closing of schools or because they have had to help parents in the gardens. Lack of money places stress on family relationships, for example, in cases where children are determined to go to school, whereas parents feel their children's and teachers' demands are excessive. Parents feel that children nowadays "need everything new," and feel that a "city mentality" (the influence of TV and the culture brought by the newly stationed national military) is to blame for this. Repeatedly, parents and others mentioned that many parents do not have the time to be with their children because they need to work to restore the family's economic standing.

Parents generally described difficulty in dealing with these problems. Some parents tried to make their children understand why there was no money for school fees and other expenses, but it was often mentioned that conflicts related to money led to disappointment, punishment and disturbed family relations. Mostly parents deal with these problems by rebuilding gardens, asking children to work in the gardens, having children live with other family members and taking loans. Children felt the necessity to assist parents, but generally seemed to focus on their own futures through school as a way of securing sought-after government positions. 


\section{Trauma and Fears}

One of the most salient illness labels, from a cross-cultural perspective, is the use of the word trauma (cf., Dwyer \& Santikarma, 2007). The word trauma was probably introduced by the humanitarian community after the conflict, but its use is reinforced in the national media, which regularly displays scenes of disasters with personal background stories. Although mostly referred to when speaking of fears, the word is employed when describing any negative psychological and social problems arising after a strongly upsetting event. Trauma is used as a broad term, encompassing differential fear-related problems after an upsetting event. It ranges from fears related to actual ongoing events to generalized fears of entities not related to the conflict such as devils and spirits (Setan, Kuntilanak, Tuyul), the dark, going to school and cloudy/bad weather.

Participant \#2: "If he hears an explosion sound, he will run away directly, his body will be cold" Participant \#8: "My child said: "Ouch, Mama we are going to die" Participant \#3: "What ... like trauma when there are sounds like that." (Excerpt from a focus group discussion with female Muslim parents, August 2005)

I have a trauma. I have to be accompanied to go to the bathroom. I am afraid of Satan. (Male 9-year-old in a semi-structured interview, October 2005)

Fears and trauma, often used interchangeably, strongly diminished when the security situation improved after the Malino accords. Trauma also encompasses fears related to, or recalling, previous violence events. The fear reactions are described as being stronger than before the start of the communal violence, and include fears occasioned by burning bamboo (which can sound like gun shots), falling coconuts, thunder, people hunting, crowds, firecrackers, strangers, people screaming and people running fast.

Fear is usually placed in the heart (hati) and referred to by somatic sensations such as trembling (gemetar), fever (demam), a drop in body temperature (suhu tubuh dingin), headache (sakit kepala), sweating (berkeringat), dizziness (pusing), a pale face (pucat), as well as going to hug parents, and a feeling of wanting to run. In some cases fainting is linked to being fearful. Although trauma is described as being caused by overwhelming fearful experiences, parents often describe it in terms of somatic problems, saying it can lead to heart attacks (serangan jantung), being easily shocked (mudah kaget), "brain problems" (masalah otak), or loss of concentration/general mental ability (kehilangan konsentrasi/ kemampuan mental umum).

Trauma and fears are mostly dealt with within the family, although in cases where complaints coincide with supernatural or somatic concerns, 
services from the folk/professional sector are sought (traditional and allopathic practitioners respectively). Parents initially deal with trauma through a combination of soothing children when they are afraid, explaining the real cause of the fear (sometimes lying if the incident was a real bomb blast or crossfire), hugging/touching, keeping children busy by giving them work or letting them play and letting children do things they enjoy.

My mother comforted me directly and asked me to calm down, there was nothing, she said, only policemen shooting birds. Mainly she convinced my heart. (13-year-old female youth in a semi-structured interview, describing her mother's reaction to her fear of gunshots)

Many parents direct children to pray and tell them that God will take care of things and that the only thing to be afraid of is God. ${ }^{2}$ The reenforcement of God as the ultimate protector and provider of justice seems to play an important role in dealing with fears and trauma. Other strategies used to discourage children from being afraid are threats or punishments. Finally, some parents directly seek out the sources of fear and let children confront them (cf., exposure based techniques in western settings), e.g., by taking children outside when they are reluctant (often after return from displacement) or taking children to directly encounter government security personnel. A typical combination of these strategies used by parents is illustrated in the following case:

\section{Case 1}

Nine-year old Mohamed has had fear-related problems since 2001, which his family members ascribe to the communal violence events. His fears are characterized by crying, trembling, and running for shelter and the safety of his mother. His fears can be triggered by bamboo burning, someone running fast, displays of aggression, or threatening events (e.g., a recent flood). His parents describe that they deal with his fears by explaining that it is only bamboo burning, or that the flood will not be as big as a previous flood. Through these explanations they aim to increase his courage and take away the fear. They emphasize that they cannot be too strict with him when he is fearful and try to persuade him to "re-strengthen his heart." The family explains the fear by saying that it overcharges the strength of Mohamed's heart. However, his soul is judged to be strong, because he is naughty. His parents also ask for the help of God through prayers. His grandfather adds that it seems like Mohamed is losing his mental capacity (kehilangan kapasitas mental).

\section{Somatic Problems}

Somatic problems are often traced to deprivation during the displacement period and overlap with the category of trauma and fear-related problems. We mention it as a separate category, because the cause of 
the problem is placed within the body and not in overwhelming experiences. Frequently mentioned somatic problems are physical weakness (lemah fisik), susceptibility to illnesses (mudah sakit), diarrhea, and vomiting. At times the distinctions between mental and physical categories are blurred.

Somatic problems are usually dealt with first in the home, by selfmedicating with allopathic or traditional medicine, prayer and massage. If these do not suffice and the problem continues, family members or neighbors will suggest a course of action that often involves a masseuse (Tukang Urut) in case of fevers and pains, or a doctor if the illness is believed to be treatable with allopathic medicine. The following case illustrates this health-seeking pattern in a child with a combination of physical and stress-related complaints.

\section{Case 2}

In 2000 three-year old Abdul and his sibling were taken to Ampana by their parents to escape the violence. During the Muslim family's flight Abdul developed a strong "fever" (deman/panas tinggi) accompanied by stiffness of the body. His maternal grandmother treated the fever by blowing mantras on his body and the fever decreased for around two hours. After several days in Ampana, the fever returned, now accompanied by wide-open motionless eyes, and the family was advised to take Abdul to a local massage healer who treated the problem on and off for a year. After return to their original village, Abdul's fever kept flaring up and he was taken to a doctor who prescribed syrup that the child disliked. The family does not return to the doctor because of associated costs and because the child does not take the syrup. When we spoke to them (Abdul was seven years old), the parents still did not know exactly how to treat the recurrent fevers and found their son's face pale.

\section{"Morally Inappropriate Behavior"}

Participants (mostly parents and general community members) described a distinctive category of problems: socially unacceptable behavior that they related to the communal violence. These problems include early sexual behavior and relations, cigarette smoking, use of drugs (alcohol, marijuana), stealing, watching movies (including pornographic and violent movies), school refusal, disobedience towards parents and elders, and the use of abusive language. Parents and teachers felt the causes of these problems were the proximity to the wrongs of communal violence and the negative influence of television and modernity. Teachers mentioned lack of attention at home.

In the family environment these problems are usually handled with advice on what to do, explaining what is right and wrong, the identification of God as an all-knowing and all-seeing retributive agent, as well 
as reward and punishment (with a focus on the latter). Government and religious schools seem to play an important role in emphasizing morally correct behavior through education (see following).

\section{Popular Sector: The School}

Within the school setting, the major problems identified are the consequences of economic hardship, morally inappropriate behavior, and interreligious tensions. Economic problems were most directly addressed at the family level (i.e., in the popular sector), and so are not discussed here. It should be noted that teachers find that these problems greatly affect schooling and try to help by waiving fees, providing pens/schoolbooks and talking to parents about the importance of schooling.

Both public and religious teachers (Sunday school and Quran reading classes) play essential roles as moral educators and consider it a priority to show children what is right and wrong. Teachers generally have the feeling that children in school are more difficult to deal with than they had previously been, pay less attention, and that children are maturing more quickly than before (e.g., sexually or in understanding of religious differences). Teachers employ a variety of strategies in which they stress the importance of collaborating with parents. The most important strategy employed is to provide advice on what is right and wrong, mostly through the words of God in the Bible or Quran and sometimes accompanied with threats ("If you fight like this you will go to hell"), punishment, and discussions with parents. In public schools, "morality and social" classes serve this purpose, as do stories, verses, songs, and sermons in religious schools.

A related difficulty in the school setting is the social distance that has developed between religious groups. The existence of religious tension was an issue of contention in the data we collected. On the one hand there were children and adults who mentioned that religious tensions still exist in a straightforward way. On the other hand, there were people who denied the presence of religious tensions and felt that relations had returned to their pre-violence state, especially when they concerned children. There were also people who, especially in discussions that involved mixed religious participants, simultaneously emphasized and denied the existence of religious tensions, most probably not to offend people of other religions. What is clear is that this is an extremely sensitive topic. The word "social" (sosial) often elicited discourse related to the communal violence of the past and inter-religious relations in the present in indirect terms (hubungan/interaksi dengan orang lain). Children's perspectives on these tensions were somewhat different. They felt that the inter-religious difficulties were something between their own and their friends' parents, 
forced upon them during the violence, but which did influence their friendships and trust afterwards.

"After the conflict nobody trusted their friends" [participant 10]. "Then, there was a difference between this and this ... Thus, we had to obey what our parents told us. However, according to us, actually nothing had happened between us, because between us we did not know anything." [participant 12]

During the period of our research, there was also increased sensitivity surrounding teasing and fighting between different religious peers.

After the return from displacement, teachers noted the gap between religious groups; children played separately, befriended and lined up during gym class separately. Teachers in public school settings with mixed religions targeted these problems through imposing increased interreligious peer interactions in class, sports, and play. One key informant describes the organization of school trips to villages of another religion (after the violence communities have become increasingly segregated in different localities) to draw the scenery, with the aim of decreasing fear. Teachers try to provide a good example by modeling inter-religious contacts in their own daily lives. Moreover, religious teachers use religious texts to encourage reconciliation (e.g., "Revenge is bad. Love thy enemy," "We are all God's children").

As a positive consequence of the communal violence, both Muslim and Protestant religious teachers and clergy described an increased cohesiveness within religious communities and a willingness to perform religious duties, as well as the possibility to learn for the future.

\section{FOLK SECTOR}

Massage healers, both Christian and Muslim and mainly female, are positioned on the boundary between popular and folk healing. People often consult healers within their own extended families, but they do possess a level of specialization, such as knowledge of mantras and herbs, and, in the case of some older healers, power over supernatural forces. Moreover, elders within the family often have knowledge of appropriate herbs to use for a variety of somatic problems. Massage healers are readily available as healers (sometimes doubling as midwives) and are consulted for somatic problems in particular (i.e., fever, fainting, pains, stiffness, sprains, injuries, swellings), but also when supernatural problems are suspected (e.g., negative influences by evil spirits/Satan, bad winds [Keteguran]). Their treatment mostly consists of massage (urut) of the body, often with coconut oil mixed with onions, on at least three occasions, until the fever or other complaint decreases. Additional manipulation of 
supernatural forces can consist of having the patient drink water that has been blown with mantras, blowing over a child's face, rubbing or spitting herbs or water over the face, or providing an amulet (jimat/penangkal bahaya). Massage oil itself is often infused with mantras through blowing. Massage healers differ in their conception of treatment mechanisms, with some describing the effect of the treatment residing in the physical massage (fixing sprains, increasing blood flow around areas with tension), whereas other more specialized healers emphasize the power of God and herbs they use. Massage healers are often visited in conjunction with health professionals, if finances allow, as illustrated in the following case.

Case 3

Seven-year old Joni was first displaced in 2000. During the days of travel he was mostly silent and refused to eat, which his parents treated with traditional medicine (obat tradisional). In the displacement camps they received medication from the health officer for the same problem. Joni's father reports that from this time Joni has been fearful; he does not want to go back to their original village, is easily shocked (mudah kaget), and is easily startled when he hears loud voices and sees people fighting. Although he is progressing at school, his teacher has complained of a lack of concentration and forgetfulness. Joni's father describes him as showing "stress" at times, when he is quiet and lacks enthusiasm. In addition, his father blames Joni's fear for his current thinness and recurrent fevers. The latter prompted them to visit a doctor at the health post (Puskesmas), but fevers continued to recur. Subsequently, a massage healer was visited who provided massage and an herb potion. Currently, his parents continue to take Joni to the health post and massage healer whenever he has a fever.

\section{Professional SeCtor}

The professional sector consists of allopathic practitioners, available through (1) the fairly accessible integrated public health posts for younger children (Posyandu) often operated by Posyandu cadres, and (2) more specialized personnel in urban centers. Health posts have a modest preventive function in providing advice on nutrition, hygiene, prevention of malaria, and other diseases. Their personnel treat illnesses such as malnutrition/dehydration, diarrhea, malaria, and respiratory tract infections. Though a number of medical professionals explained the necessity of the power of God for healing to occur, most articulated biomedical ideas regarding healing. Participants often use different helpseeking strategies simultaneously, as illustrated in the following case.

Case 4

7-year-old Dani experiences a weeklong fever accompanied by stiffness, which is treated with medication received from a midwife. When the fever 
returns he falls unconscious and is hospitalized in Parigi. When there is no change after a week, his family has him transferred to the Salvation Army hospital, where a nervous tissue sample is taken and an infection is diagnosed. During his unconscious periods Dani utters abusive sexual language, kicks and shouts, and speaks of an attack at the village, bomb blasts and shooting. The doctor and nurses explained this by saying he is "traumatized." During this time a church-affiliated volunteer comes to assist in prayer. After his return home, the parents say his attitude has changed: Dani is disobedient, often asks for money, and rages violently when he does not get what he wants. His mother expresses helplessness as to how to handle this behavior, tries to give what he asks for, tries to be patient, and asks God for assistance.

Midwives and doctors expressed their concern about the same psychosocial consequences of communal violence as did massage healers and other participants. On the whole, however, they did not see a role for their professions in dealing with these problems, explaining that such issues were treated within families or were not serious enough to refer to the psychiatrist or the mental health hospital in urban Palu. There seemed to be a gap between what practitioners mentioned as their concerns as members of their community, and what they felt they could treat as medical professionals.

If the child is not in a serious condition, I only give him/her medicines. During these times, I have never found a patient, who is in a very serious condition, like seriously stressed. I have never found such types of patients, only the common ones. (40-year-old female doctor working for the public health service on November 26, 2005)

On the other hand, one public health worker was active in trying to "increase cooperation between children through sports" and one older midwife had observed increased aggression during play ("Seeing children slice each other's neck when playing with swords"), and sought to give parents advice for dealing with such aggression.

Besides the planned activities of the humanitarian partner with whom the research was conducted, no humanitarian organizations were specifically focusing on psychosocial issues in the communities researched.

\section{Discussion}

The research described here aimed at examining the health care system relevant to communal violence and its psychosocial consequences prior to a cluster randomized trial evaluating a school-based psychosocial intervention (Tol et al., 2008) by assessing how people in violence-affected communities describe the psychosocial impact of armed conflict on 
children, and by exploring what is being done in violence-affected communities to address this impact. Children and adults in this study describe a closely-related set of problems that includes poverty, trauma and fears, morally inappropriate behavior, inter-religious tensions, and somatic problems. A variety of social actors concern themselves with these problems. The vast majority of the problems were being treated in the family environment. The implications of these data in terms of programming and further research are discussed below. However, we first mention a number of limitations to our study design.

\section{LIMITATIONS}

Several limitations of this study must be noted. First, the study was carried out in a relatively short period of time, with pre-formatted interview schedules, comparable to a participatory rapid appraisal approach. This made it difficult to sample purposively, i.e., to fill gaps in evolving theory. We did feel, however, that the amount of data, the different informants (lay and experts; children, their parents, and other adults), and the different interview settings (individual and group) provided sufficient opportunities for triangulation (Strauss \& Corbin, 1998). Nevertheless, we were not able to reach the desired depth in enquiry regarding a number of issues, such as the current state of inter-communal tensions and how they are addressed (e.g., at schools, between villages), power relations between actors at different social-ecological levels (e.g., the tensions between teachers and parents or between the community members and military presence), or perceived effectiveness of services provided for traumarelated complaints within the folk sector. Although we were able to point to their importance in this exploratory study, further ethnographic research is needed to fill these gaps in our knowledge.

Second, we sampled areas rather than individual participants, which is the likely reason for an over-representation of Christian participants in the semi-structured interviews. Furthermore, data was collected by trained interviewers from the region where data was collected. Although this greatly enhanced our accessibility to the target participants, it did on occasion result in questioning being less thorough than it could have been. Local interviewers, because of habituation, may have been less inclined to view social variables as new and worthy of further investigation.

Third, we worked through a locally active humanitarian organization. To counter any bias potentially caused by this association we chose areas where the organization was not operative at the time and we emphasized throughout research that participation would not lead to benefits in services. It is possible, however, that participants might have stressed vulnerability in their narratives in expectation of services. 
Finally, this study was part of a public mental health program that was intended to provide services to children affected by political violence. Though we used an open-ended qualitative inquiry approach, we could have introduced bias by working from the perspective that external assistance was, in fact, needed.

\section{PROGRAMMATIC IMPLICATIONS}

In terms of implications for psychosocial intervention, a number of recommendations emerged from this study. First, our data suggest that rather than an exclusive individual focus on trauma, interventions should address the wider damage to the social fabric described by participants. Interventions in this continuing unstable situation, in our opinion, should focus on economic reconstruction, addressing economic inequality and its effects on family and neighborhood relations.

In addition, a generational conflict seems to have emerged in parents' perception of immoral behavior on the part of children. Participants blame this on children having witnessed conflict events, parents focusing on livelihood (re)construction, children dropping out of school, and the influence of modernity underscored by the presence of the national military. Poverty alleviation, e.g., through micro-credit schemes, could go hand-in-hand with interventions aimed at closing this widening gap between parents and children. For example children who have left school could be encouraged to join youth groups to participate in activities valued by both younger and older generations.

Furthermore, we recommend that interventions address the reported damage to inter-religious communal relations. During the years of communal violence previously mixed religious neighborhoods have become segregated. Though the communal violence might not be specifically rooted in religious differences, our study participants did express alienation from people of other religions as a result of the hostilities, e.g., children expressed fear of people of other religions and this was generally perceived as an extremely sensitive subject. We refer here to the doubleedged sword of community cohesion within religious communities expressed as a positive consequence of violence. On the one hand this might be a protective factor for individual wellbeing within a community, but it might also increase the risk of further violence (cf. Laor et al., 2006).

Second, we argue that interventions will likely be more sustainable if they build upon efforts being currently undertaken to deal with distress. Most children's difficulties associated with violence are handled within the family sphere. However, participants stressed the challenges presented to the protective function of the family in the form of economic hardship and continued insecurity. A good initial focus for external psychosocial 
support would thus be groups of parents in violence-affected areas. Research in other areas affected by political violence has highlighted the importance of parental functioning for children's functioning (Qouta, Punamaki, \& el Sarraj, 2005), and interventions have shown hopeful improvements in child well-being when working with mothers of younger children (Dybdahl, 2001).

The group of people we categorized under the folk and professional sector would currently be well placed to provide assistance. Massage healers, who are generally respected and easily accessible, play important roles in relieving somatic and supernatural problems. More focused research could explore how massage healers themselves believe how they could be helpful in assisting children with trauma and fears and morally inappropriate behavior. Similarly, the professional sector (Posyandu cadres, midwifes, doctors), while describing the same problems associated with political violence as other participants, did not see a role for their professions in dealing with the psychosocial impact of the conflict. Mental problems were highly stigmatized and this might be a reason for a lack of connection between the public health sector and community perspectives. Current consensus has promoted the integration of psychiatric care for common mental disorders (anxiety, depression, somatoform disorders) in primary care and community structures (e.g., Patel, 2008). Access to primary care that is cost-effective and culturally appropriate could lead to decreased stigma associated with mental health problems.

\section{RESEARCH IMPLICATIONS}

As mentioned, we expected results of this study to feed into the design and evaluation of a public mental health program for children affected by political violence in the region. In terms of the design of the evaluation study, we (1) selected standardized quantitative questionnaires that seemed relevant in light of the categories of problems stated by our participants, and (2) added a group of items referring to the somatic trauma complaints, which we felt were not represented in standardized instrumentation. Moreover, in a procedure described separately (Tol, Komproe, Jordans, Susanty \& De Jong, under review), we constructed a tool to measure function impairment, based on locally relevant activities.

While we found Kleinman's division of the health care system in popular, folk and professional sectors a useful way of presenting the diverse psychosocial impacts and efforts undertaken to address these impacts, there may be some limitations to the presentation of our data through this model. Kleinman's division (1980) was developed in relation to health care and its application to more broadly defined notions of psychosocial wellbeing may be problematic in certain instances. For 
example, immoral behavior by children was not necessarily described as an illness by participants. Moreover, strict application of Kleinman's model carries the risk of not acknowledging children as potential actors. In an adult-centered model, it easier to conceive of children as receivers of care, than as agents who actively cope with difficulties. For example, children wanted to attend school as a means of dealing with poverty, which at times was not compatible with their parents' strategies for financial recovery.

In general, as described in the introduction, two dominant scientific paradigms (biomedical and social science) have, on the whole, separately researched and debated the psychosocial consequences of collective violence on children. We argue that our data suggests that there is the possibility for interdisciplinary enquiry, rather than the sometimes polemic debate that has characterized previous work. From a social science perspective, the psychosocial problems identified refer to "social suffering," a category of suffering which "results from what political, economic, and institutional power does to people, and reciprocally from how these forms of power themselves influence responses to social problems," (Kleinman, Das, \& Lock, 1997, p. ix). In our data, similarly, the established categories that separate health, welfare, moral and religious issues, are shown to be arbitrary: it is hard to understand (mental) health matters without taking into account moral and religious issues, as participants themselves stress the links between psychosocial problems at the individual level and the wider economic and political context in their communities and at the national level. From a universalist perspective it can be argued that these data show that individual psychological problems (i.e., trauma) are mentioned by participants, hold local relevance, and partly resemble supposed biological-behavioral mechanisms of generalized fear after upsetting events (cf. De Jong, 2005; Marsella, Friedman, Gerrity, \& Scurfield, 1996).

Moreover, some parents described a self-designed form of in-vivo exposure, an evidence-based psychotherapeutic technique for traumarelated problems in high-income settings, suggesting at least a partial overlap in local and "Western" psychological treatment mechanisms. There is growing consensus that intervention programs should build on available coping strategies in the local culture (cf. De Jong \& Van Ommeren, 2002). We think that the presence of this indigenous form of exposure as well as the aforementioned form of cognitive restructuring by parents could be incorporated and strengthened in the development of a psychosocial intervention program.

However, our data also show that trauma is a highly indigenized construct, embedded in a larger integrated set of post-communal violence problems that include poverty, inter-generational conflict and change, 
changed inter-religious relations, and a damaged moral fabric. Trauma is not equivalent to a psychological category that can be exclusively treated with evidence-based individual treatment from high-income settings, without taking into account the larger social context. Trauma is embedded in a broader social process in which a previous sense of safety, predictability and organization seems lost. Moreover, social changes catalyzed by the armed conflict and related to modernization (satellite television, increased urban-village contacts, influence by the military) are blamed as causes for morally inappropriate behavior. Individual psychological problems must thus also be seen in the historical context of Indonesian state building, changed economic relations and political changes in which the conflict is partly rooted, as well as changes related to modernization and globalization. In other words, a narrow focus on a stressor-trauma relationship causing individual distress would miss the point that participants themselves make regarding the nature of individual problems being embedded within the family, school, and larger community context.

Our data raises questions that need to be answered to better understand and relieve suffering. Moreover, these questions, in our opinion, call for interdisciplinary (and multi-level) research. For instance, how are socially disruptive processes that go hand-in-hand with discrete exposure events translated over time into individual psychobiological dysfunction (cf. Waitzkin \& Magana, 1997)? How are they translated into local idioms of distress, combining culturally accepted processes of dissociation (e.g., fainting as described in the cases of Abdul and Dani), metaphors and ethno-physiological sensations (cf. Hinton, Pich, Chhean, \& Pollack, 2005)? How are massage healers able to work with these somatic concerns, and thereby relieve psychological and social suffering (cf. Kirmayer, 2004)? How does the continued individual suffering of a minority of people after communal violence affect collective notions of morality and social harmony? Which social consequences of violence have the largest predictive value of negative health consequences after communal violence?

In conclusion, this qualitative study, carried out in resource-poor violence-affected settings with locally available research resources, illustrates how children, parents, teachers, and community members describe the effects of communal violence on psychosocial well-being, and the resources that are employed to manage these effects. We recommend psychosocial programs that focus on the wider damage to society associated with political violence (economic reconstruction and disturbed inter-communal relations), which strengthen the family's protective function, and increase engagement of the folk and professional health care sector. Our data suggest the need for interdisciplinary research to bridge the paradigms through which the impacts of collective violence on individuals and communities have, to date, been studied. 


\section{Notes}

1. We follow the Psychosocial Working Group (2003) in our use of the word psychosocial, i.e., to emphasize the close connection between psychological aspects of experience and wider social aspects of experience, inclusive of human capacity, social ecology, and culture and values.

2. As the analysis in this article does not compare responses on the basis of our interlocutors' religion, references to "God" indicate the views of both Christians and Muslims, unless otherwise indicated.

\section{REFERENCES}

Arafat, C., \& Boothby, N. (2003). A psychosocial assessment of Palestinian children. Washington, DC: USAID.

Aragon, L. V. (2001). Communal violence in Poso, Central Sulawesi: Where people eat fish and fish eat people. Indonesia, 72, 45-79.

Barenbaum, J., Ruchkin, V., \& Schwab-Stone, M. (2004). The psychosocial aspects of children exposed to war: practice and policy initiatives. Journal of Child Psychology \& Psychiatry, 45, 41-62.

Berman, H. (2001). Children and war: current understandings and future directions. Public Health Nursing, 18, 243-252.

Betancourt, T. S., \& Williams, T. (2008). Building an evidence-base on mental health interventions for children affected by armed conflict. Intervention: International Journal of Mental Health, Psychosocial Work \& Counselling in Areas of Armed Conflict, 6, 39-56.

Boothby, N., Strang, A., \& Wessels, M. (2006). A world turned upside down: Social ecological approaches to children in war zones. Bloomfield, CT: Kumarian Press.

Boyden, J. (2000). Social healing in war-affected and displaced children. Oxford: University of Oxford Refugees Studies Centre

Boyden, J., \& de Berry, J. (2006). Introduction. In J. Boyden \& J. de Berry (Eds.), Children and youth on the front line: Ethnography, armed conflict, and displacement. New York: Bergahn Books.

Brown, G., Tajima, Y., \& Hadi, S. (2005). Overcoming violent conflict, Vol. 3: Peace and development analysis in Central Sulawesi. Jakarta: UNDP.

Das, V., \& Reynolds, P. (2003). The child on the wing: Children negotiating the everyday in the geography of violence. Baltimore, MD: Johns Hopkins University, Department of Anthropology.

De Jong, J. T. V. M. (2002). Public mental health, traumatic stress, and human rights violations in low-income countries. In J. T. V. M. de Jong (Ed.), Trauma, war, and violence: Public mental health in socio-cultural context (pp. 1-91). New York: Kluwer Academic/Plenum Publishers.

De Jong, J. T. V. M. (2005). Commentary: Deconstructing critiques on the internationalization of PTSD. Culture, Medicine and Psychiatry, 29, 361-370.

De Jong, J. T. V. M., \& Van Ommeren, M. (2002). Toward a culture-informed epidemiology: Combining qualitative and quantitative research in transcultural contexts. Transcultural Psychiatry, 39, 422-433. 
Dwyer, L., \& Santikarma, D. (2007). Posttraumatic politics: violence, memory, and biomedical discourse in Bali. In L. J. Kirmayer, R. Lemelson, \& M. Barad (Eds.), Understanding trauma: Integrating biological, clinical and cultural perspectives (pp. 403-432). Cambridge: Cambridge University Press.

Dybdahl, R. (2001). Children and mothers in war: an outcome study of a psychosocial intervention program. Child Development, 72, 1214-1230.

Hart, J., \& Tyrer, B. (2006). Research with children living in situations of armed conflict: Concepts, ethics \& methods. Oxford: Queen Elizabeth House, Department of International Development, University of Oxford.

Hinton, D. E., Pich, V., Chhean, D., \& Pollack, M. H. (2005). The ghost pushes you down: Sleep paralysis-type panic attacks in a Khmer refugee population. Transcultural Psychiatry, 42, 46-77.

Hohmann, A. A., \& Shear, M. K. (2002). Community-based intervention research: Coping with the "noise" of real life in study design. American Journal of Psychiatry, 159, 201-207.

Human Rights Watch. (2002). Breakdown: Four years of communal violence in Central Sulawesi. Washington, DC: Human Rights Watch.

International Crisis Group. (2004). Indonesia backgrounder: Jihad in Central Sulawesi. Jakarta and Brussels: International Crisis Group.

Joshi, P. T., \& O’Donnell, D. A. (2003). Consequences of child exposure to war and terrorism. Clinical Child \& Family Psychology Review, 6, 275-292.

Kirmayer, L. J. (2004). The cultural diversity of healing: meaning, metaphor and mechanism. British Medical Bulletin, 69, 33-48.

Kleinman, A., Das, V., \& Lock, M. M. (Eds.) (1997). Social suffering. Berkeley: University of California Press.

Kleinman, A. (1980). Patients and healers in the context of culture: An exploration of the borderland between anthropology, medicine, and psychiatry. Berkeley: University of California Press.

Korbin, J. E. (2003). Children, childhoods, and violence. Annual Review of Anthropology, 32, 431-446.

Laor, N., Wolmer, L., Alon, M., Siev, J., Samuel, E., \& Toren, P. (2006). Risk and protective factors mediating psychological symptoms and ideological commitment of adolescents facing continuous terrorism. Journal of Nervous \& Mental Disease, 194, 279-286.

Marsella, A. J., Friedman, M. J., Gerrity, E. T., \& Scurfield, R. M. (1996). Ethnocultural aspects of PTSD: some closing thoughts. In A. J. Marsella, M. J. Friedman, E. T. Gerrity, \& R. M. Scurfield (Eds.), Ethnocultural aspects of posttraumatic stress disorder: Issues, research, and clinical applications. Washington, DC: American Psychological Association.

Miller, K. E., Kulkarni, M., \& Kushner, H. (2006). Beyond trauma-focused psychiatric epidemiology: Bridging research and practice with war-affected populations. American Journal of Orthopsychiatry, 76, 409-422.

Miller, K. E., \& Rasco, L. M. (2004). The mental health of refugees: Ecological approaches to healing and adaptation. Mahwah, NJ: Lawrence Erlbaum Associates.

Patel, V. (2008). Promoting child and adolescent mental health in low and middle income countries. Journal of Child Psychology \& Psychiatry, 49, 313-334. 
Pedersen, D. (2002). Political violence, ethnic conflict, and contemporary wars: broad implications for health and social well-being. Social Science \& Medicine, 55, 175-190.

Psychosocial Working Group. (2003). Psychosocial intervention in complex emergencies: A conceptual framework. Oxford: Refugees Studies Centre.

Qouta, S., Punamaki, R. L., \& el Sarraj, E. (2005). Mother-child expression of psychological distress in war trauma. Clinical Child Psychology and Psychiatry, $10,135-156$.

Shaw, J. A. (2003). Children exposed to war/terrorism. Clinical Child \& Family Psychology Review, 6, 237-246.

Stichick, T. (2001). The psychosocial impact of armed conflict on children: Rethinking traditional paradigms in research and intervention. Child \& Adolescent Psychiatric Clinics of North America, 10, 797-814.

Strauss, A., \& Corbin, J. (1998). Basics of qualitative research: Techniques and procedures for developing grounded theory. Thousand Oaks, CA: Sage.

Summerfield, D. (2000). Childhood, war, refugeedom and "trauma": three core questions for mental health professionals. Transcultural Psychiatry, 37, 417-433.

Tol, W. A., Komproe, I. H., Jordans, M. J. D., Susanty, D., \& De Jong, J. T. V. M. (under review). Developing a function impairment measure for children affected by political violence: A mixed methods approach in Indonesia.

Tol, W. A., Komproe, I. H., Susanty, D., Jordans, M. J. D., Macy, R. D., \& De Jong, J. T. V. M. (2008). School-based mental health intervention for children affected by political violence in Indonesia: A cluster randomized trial. JAMA, 300, 655-662.

Waitzkin, H., \& Magana, H. (1997). The black box in somatization: unexplained physical symptoms, culture, and narratives of trauma. Social Science \& Medicine, 45, 811-825.

Wexler, I. D., Branski, D., \& Kerem, E. (2006). War and children. JAMA, 296, 579-581.

World Health Organization (2001). Rapid assessment of mental health of refugees, displaced, and other populations affected by conflict and post-conflict situations, and available resources. Geneva: World Health Organization.

Wietse A. Tol received a Masters degree in Clinical \& Health Psychology from Leiden University and a PhD degree from the VU University Medical Center (Amsterdam, the Netherlands). He works as a senior technical advisor for HealthNet TPO and TPO Nepal. His intervention and research interests concern the design, implementation and evaluation of mental health and psychosocial projects for populations exposed to political violence and other emergencies in low-income settings. Address: c/o HealthNet TPO, Department of Research \& Development, Tolstraat 127, 1074 VJ, Amsterdam, The Netherlands.

[E-mail: wtol@healthnettpo.org]

Ria Reis, MA, PhD, is Professor of Medical Anthropology, in particular Anthropology in Public Health at Leiden University Medical Centre, and Associate Professor at the University of Amsterdam, Faculty of Social Sciences. She is 
(co)chair of the research program Anthropology of Health, Care and the Body at the Amsterdam Institute for Social Science Research (AISSR) and director of an international postgraduate program in applied medical anthropology (AMMA). Her current research focus is on perceptions and strategies of children and youth regarding health and illness and the articulation of child focused ethnography within quantitative research designs and health interventions. [E-mail: r.reis@uva.nl]

Dessy Susanty received a Master degree in Clinical Psychology from Edith Cowan University. She is working with Church World Service Indonesia as a monitoring and evaluation officer and has been involved in implementation and evaluation of psychosocial projects in disaster areas (natural disasters and armed conflict) for several years. [E-mail: dessy@cwsindonesia.or.id]

Joop T.V.M. DE Jong, MD, PhD, is Professor of Cultural and International Psychiatry at the VU University in Amsterdam and Adjunct Professor of Psychiatry at Boston University School of Medicine. He is Principal Advisor Socio-medical Projects and Public Mental Health of the Amsterdam Municipality. He was the founder and director of the Transcultural Psychosocial Organization, a NGO that developed psycho-social and mental health programs in Africa, Asia, Europe and Latin America. Joop de Jong publishes in the field of cultural psychiatry and psychotherapy, epidemiology, public mental health and medical anthropology. [E-mail: jtvmdejong@gmail.com] 